\title{
One New Species of the Genus Dryomys (Rodentia, Glirgae) from Xinjiang China, Dryomys Yarkandensis sp. nov
}

\author{
L. $\mathrm{LIAO}^{1}, \mathrm{R} \cdot \mathrm{AN}^{1}, \mathrm{~S} \cdot \mathrm{SHI}^{1}, \mathrm{Y} \cdot \mathrm{XU}{ }^{1}, \mathrm{Y} \cdot \mathrm{LUO}^{1}, \mathrm{~W} \cdot \mathrm{LIAO}^{2}$ \\ ${ }^{1}$ Center for Disease Control and Prevention in Xinjiang, Urumqi, Xinjiang, P.R. China, 830002. \\ ${ }^{2}$ Capital Normal University, Beijing, P.R. China, 100048.
}

Ran AN: No. 380 Jianquan First Steet, Urumqi, Xinjiang, P.R. China, 830002.

E-mail: anranxj@sina.com. Tel: +86-18799191903.

Shen SHI: No. 380 Jianquan First Steet, Urumqi, Xinjiang, P.R. China, 830002.

E-mail: shishen534@163.com. Tel: +86-13565836695.

Yimei XU: No. 380 Jianquan First Steet, Urumqi, Xinjiang, P.R. China, 830002.

E-mail: 545763836@qq.com. Tel: +86-18999918683.

Yun LUO: No. 380 Jianquan First Steet, Urumqi, Xinjiang, P.R. China, 830002.

E-mail: sixiyun@qq.com. Tel: +86-13565886193.

Weichen LIAO: No. 105 Xisanhuan North Road, Beijing, P.R. China, 100048.

E-mail: weichen.liao@cnu.edu.cn. Tel: +86-15810601881.

Corresponding author: Lifu LIAO: No. 380 Jianquan First Steet, Urumqi, Xinjiang, P.R. China, 830002. E-mail: liaolif@sina.com. Tel: +86-13669903215.

\begin{abstract}
During an expedition in June 2012 in Shache county of Tarim Basin in southern Xinjiang, China, a new species of the genus Dryomys (Gliridae) has been discovered and named Dryomys yarkandensis $s p$. nov. It has been found obviously different from D. nitedulai in northern Xinjiang, D. laniger, D. niethammeri and D. nitedulai in Europe, which are also belong to genus Dryomys. The new species Dryomys yarkandensis sp. nov is described below.

Holotype: No. N07, an adult female collected by Chen Zhenhai in June 2012, is deposited Center for disease prevention and control of Xinjiang (Xinjiang CDC). It was obtained from oasis orchard of desert in Tarim Basin $\left(38^{\circ} 29^{\prime} \mathrm{N}, 77^{\circ} 32^{\prime} \mathrm{E}\right), 1211-1215 \mathrm{~m}$.

Genus character: There is a dark chestnut round eye. The terminal of tail is club shape, covered with dense hairs, and cannot see the scale ring in external texture.

Description of the species: The eyes is large. The beard is long and the longest could reach 30 $\mathrm{mm}$. The tail is thicker and slightly longer than body length about $10 \%$. The terminal of the tail is fluffy. All the surface is covered with dense hairs.

External figure: The color of the new species on the back is lighter than that of $D$. laniger, $D$. niethammeri and D. nitedulai in Dryomys. The length of the tail is about $110 \%$ of the body length.
\end{abstract}


The length of the ears is $12.8 \mathrm{~mm}$, which is $15 \%$ shorter than the other three species of Dryomys.

Skull and tooth: The ratio between the length of audirory bullae and the breadth of auditory bullae is $1.66(8.35 / 5.02)$, which is larger than the other three species of $D$. nitedula.

The habitats of the new species is harsh, drought and hot in summer but dry and cold in winter. The habitats of $D$. nitedula in mountain valley in northern Xinjiang is temperate, humidity and low temperature, and there are berries or orchard.

Key Words: Dryomys yarkandensis sp. nov, New species, Tarim Basin, Gliridae

\section{Introduction}

Dryomys nitedula (Pallas, 1779) is the mode species established the genus Dryomys of family Gliridae (Thomas, 1906). It distributes extensively in central and southeastern Europe (Kryštufek and Vohralik, 1994), northern and eastern Russia, Turkey, the Middle East, Afghanistan, Pakistan, central Asia (Ognev, 1940; Allen, 1940; Sisson and Grossman, 1950; Bosessneck and Driesch, 1976; Sokolov, 1977; Sludskii, 1977; Kryštufek, 1999; Airapetyants and Fokin, 2005), as well as eastward to Dzungarian Alatau, Sawuer mountain, altai mountains in China and Khovd river upstream in western Mongolia (Shiirevdamba et al., 1997). D. nitedula lives in a wide range of habitats, including broad-leaved, mixed and coniferous woodlands, as well as rocky areas, dwarf mountain woodland, evergreen shrubland and wood-steppe (Kryštufek, 1999).

More than half a century, it has been considered as a monotype genera. According to previous work (Ellerman and Morrison-Scoot, 1951), 20 names species or subspecies of the genus had been published by 1946. But many taxonomists thought they are synonyms of $D$. nitedula (Огнев, 1947; Ellerman and Morrison-Scoot, 1951). In 1968, Felton and Storch considered that the specimen of forest dormice, which was collected from the Turkish Anatolia Rocky Mountains, is different from $D$. nitedula in terms of size and morphology characteristics, so they published a new species, Dryomys laniger (Felton and Storch, 1968). Later, Dryomys niethammeri, a new species of Dryomys collected from Pakistan's baluchistan province, was described and compared the morphology with D. nitedula and D. laniger (Holden, 1996). The research conclusions were recognized by another work (Rossolimo et al., 2001). At present, there are three species of the genus Dryomys, D nitedula, D. laniger and D. niethammeri.

Up to now, there is only one species of the genus Dryomys in China, D. nitedula, which distributes in Tianshan mountain, Altai mountain, Dzungarian Alatau and Yili basin (Wang and Yang, 1983; Ma et al., 1987; Zhang, 1997). In 2012, we obtained some specimens of dormice from oasis orchard of desert in Tarim Basin of southern Xinjiang, China. The specimens are similar to D. nitedula, but has morphological differences from D. nitedula. In order to find out its classification status, we collected living specimens to breed in lab from Shache county in Tarim basin of southern Xinjiang and form Jinghe county of northern Xinjiang in 2013. We compared the specimens from the two areas from adult to larval according to morphological feature. 


\section{Part 1 Study of morphology on the dormice from Tarim basin in China}

\section{Materials}

Specimens of the dormice from Tarim basin: $\mathrm{n}=15$.

Specimens of $D$. nitedulai from northern Xinjiang in China: $\mathrm{n}=11,6$ specimens from mountains of northern Xinjiang deposited in Institute of Zoology, Chinese Academy of Sciences, including one from Altai, one from Fukang, one form Manas, one from Nileke counties, two from Talbahatai mountain of Tacheng prefecture and five from Jinhe county deposited in Xinjiang CDC Herbarium.

Dryomys nitedulai: the data of 85 specimen are quoted from previous work (Holden, 1996).

Dryomys laniger: the data of 17 specimen are quoted from previous work (Felten and Storch, 1968).

Dryomys niethammeri: the data of 3 specimen are quoted from previous work (Holden, 1996).

\section{Methods}

Age criteria: Specimens were assigned to larvae, juveniles and adult age primarily according to the body length, degree of tooth wear and the time of actual breeding.

Sexual dimorphism: Krystufek (Krystufek, 1985) found no statistically significant differences of morphology between males and females.

Color comparison: We compared the color of specimens from Tarim basin and northern Xinjiang with different ages, areas and collecting seasons.

Morphologic Measurements: The measurement methods were described in previous work (Holden, 1996; Yang et al., 2005; Xia et al., 2006). Cranial and dental measurements were taken with dial calipers graduated to tenths of millimeters. Skin color and body weights were recorded by collectors on the original skin tags. Measurements are abbreviated in the text as follows:

$\begin{array}{ll}\text { LHB } & \text { length of head and body } \\ \text { LT } & \text { length of tail } \\ \text { LHF } & \text { length of hind foot } \\ \text { LE } & \text { length of ear } \\ \text { CIL } & \text { condylo-incisive length } \\ \text { ZB } & \text { zygomatic breadth } \\ \text { IB } & \text { interorbital breadth } \\ \text { BBC } & \text { breadth of braincase } \\ \text { BR } & \text { breadth of rostrum } \\ \text { LN } & \text { length of nasals } \\ \text { LD } & \text { length of diastema } \\ \text { LBP } & \text { length of bony palate } \\ \text { LIF } & \text { length of incisive foramina } \\ \text { BIF } & \text { breadth of incisive foramina }\end{array}$


CLM1-3 crown length of M1-M3

PPL post-palatal length

LB length of audirory bullae (to the anterior margin of the paraoccipital process)

BB breadth of auditory bullae

BBO breadth of the basioccipital

Statistical analysis: The measure data were analyzed by Origin7.5 (Data Analysis \& Scientific Graphing Origin). Differences between the two groups of the specimens were tested by t-tests.Significant differences were considered according to the average value and standard deviation, in which $\mathrm{a} \leq 0.05$.

Ratio diagram: We used exactly the same method as Holden to make ratio diagram (Holden, 1996).

Principal components analysis: A principal components analysis was performed by Origin7.5 on variance-covariance matrix computed from seven log-transformed dimensions: length of body, length of tail, length of ear, length of incisive foramina, breadth of incisive foramina, length of audirory bullae and basioccipital breadth. These particular dimensions are chosen because they are informative and obtainable from most specimens. Other measurements available from the same set of specimens have relatively low scores and do not aid in separation of the samples in multivarate space when included (Holden, 1996).

Etymology: The species is named according to place where specimens were collected, i.e. Tarim (the largest basin in China).

\section{Part 2 Dryomys yarkandensis sp. nov from Tarim (a new species)}

\section{Information of the new species}

Holotype: No. N07, an adult female collected by Zhenhai Chen in June 2012, is deposited Center for disease prevention and control of Xinjiang (Xinjiang CDC). It was obtained from oasis orchard of desert in Tarim Basin $\left(38^{\circ} 29^{\prime} \mathrm{N}, 77^{\circ} 32^{\prime} \mathrm{E}\right), 1211-1215 \mathrm{~m}$. The measurements are listed in table 1.

Allotype: No. N32, an adult male deposited in Xinjiang CDC, was obtained from Tarim Basin in June 2012. The rest information is the same as holotype.

Paratype: No. N9, an adult female, is deposited in Institute of Zoology, Chinese Academy of Sciences. No. N27, an adult female, is deposited in Xinjiang CDC. The rest information is the same holitype.

The other 11 adult female specimens deposited in Xinjiang CDC, were obtained from Tarim Basin at the same time. The rest information was as same as holotype. All the measurement data are listed in table 1.

Contrast samples: Specimens of $D$. nitedula from northern Xinjiang, $\mathrm{n}=11$.

Pups picture: 16-day-old and 26-day-old pups of both D. nitedula collected in Jinghe county 
and the new species collected in Shache county were all bred in laboratory (figure 1c,d,e,f). All the measurement data are listed in table 1,2.

Table 1. The measurements of Dryomys yarkandensis sp. nov.

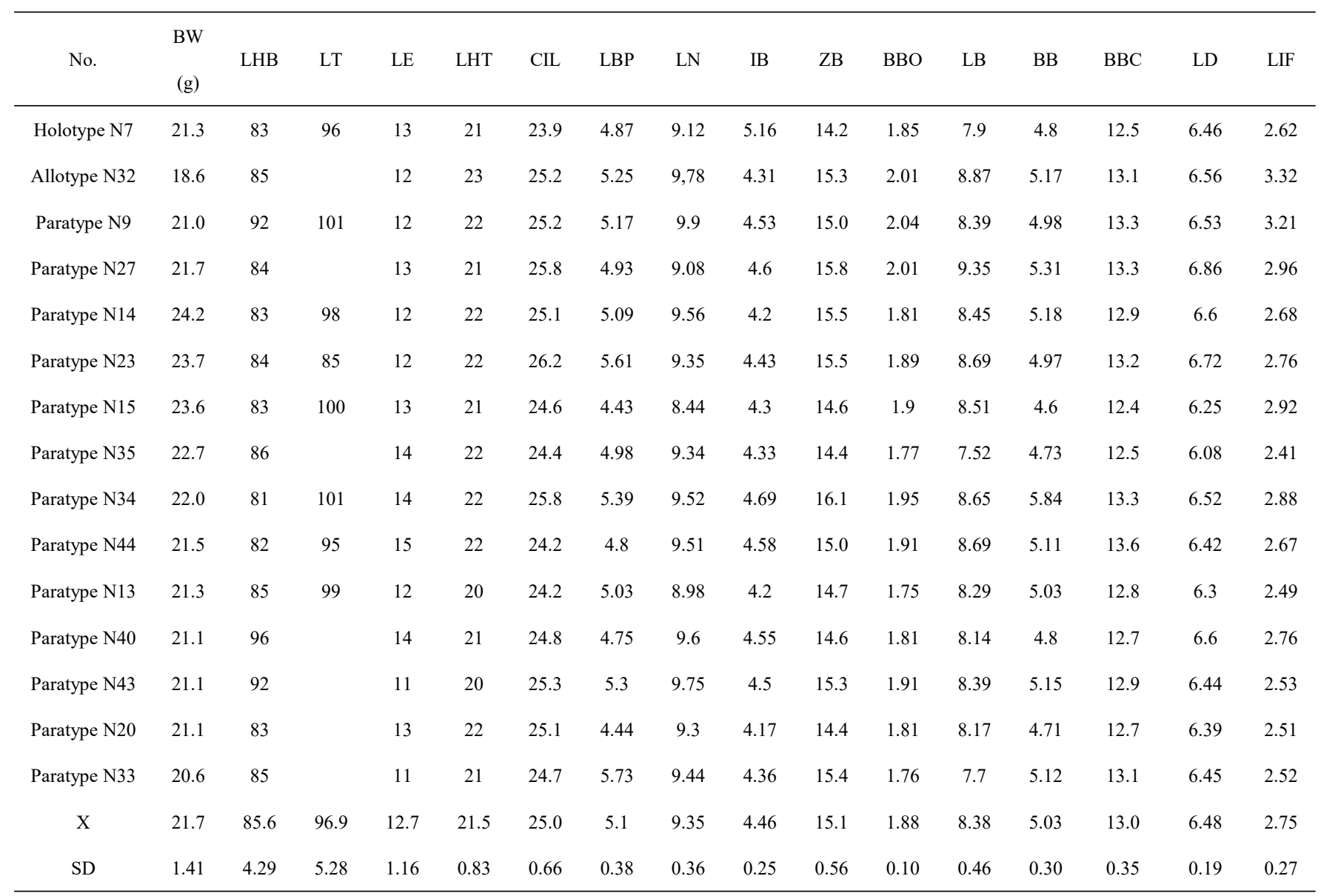

\section{Description of holotype of the new species}

Appearance: Its appearance is squirrel-like. Coat on the body and tail is heavy and soft, on the caudal is longer. There is a light black stripe from ear root through the eye to nose on both sides of the head each (figure 1a,b). The range of its body mass is between 16 grams and 30 grams. The average length of body is 85.6 (81-96) $\mathrm{mm}$ and length of the tail is $96.88(85-101) \mathrm{mm}$, which is $110 \%$ of the body length. Ears short and rounded, its average length is $12.8(11-15) \mathrm{mm}$. The length of hind foot is $21.4(20-22) \mathrm{mm}$. There are four toes on the fore foot and five toes on the hind foot, on which there are six pads. The bilateral symmetry whiskers form a bushy tuft about 25-30 mm long.

Physical description: The back color of adult is hazel in Summer, and turn light brown after Autumn gradually, which close to tail color. Hair tip of belly is cream yellow, and root hair of belly is white. There is the boundary line between side of the body and belly, and the color of tail is dark than the back, light brown, and abdominal hair of tail slightly shallow.

There is light chestnut from the head to back of pup between 16-day-old and 26-day-old after birth, and a white on belly. At autumn the color of back and tail are turn light brown, hair tip of 
belly become cream yellow. Also the color of tail is dark than back and the boundary line between side of the body and belly become clear (figure 1a,c,e).

Table 2. Compare of measurements between D. yarkandensis sp and D. nitedula from northern Xinjiang.

\begin{tabular}{|c|c|c|c|c|c|}
\hline \multirow{2}{*}{ Measurement } & \multicolumn{3}{|c|}{ Average \pm SD (n) mm } & \multirow{2}{*}{ T-test } & \multirow{2}{*}{ Difference $\mathrm{e}^{\#}$} \\
\hline & Holotype N7 & D. $y(14)$ & D. $n(11)$ & & \\
\hline Body weight (g) & 21.3 & $21.91 \pm 1.166$ & $26.4 \pm 4.0$ & $P=0.0014^{*}$ & -13.92 \\
\hline Head \&body length & 83.6 & $85.64 \pm 4.448$ & $92.73 \pm 6.51$ & $P=0.0063^{*}$ & -7.51 \\
\hline Tail length & 96 & $96.88 \pm 3.276$ & $93.9 \pm 8.61$ & $P=0.2319$ & 4.54 \\
\hline Ear length & 13 & $12.79 \pm 1.188$ & $16.45 \pm 2.69$ & $P=0.00014^{* *}$ & -19.2481 \\
\hline Hind foot length & 21 & $21.36 \pm 0.745$ & $20.27 \pm 2.28$ & $p=0.2522$ & 2.68 \\
\hline CIL & 23.9 & $24.94 \pm 0.682$ & $25.74 \pm 1.14$ & $P=0.1352$ & -5.83 \\
\hline Condylobasal length & 22.6 & $24.01 \pm 0.775$ & $24.67 \pm 1.69$ & $P=0.2356$ & 0.99 \\
\hline LBP & 4.9 & $5.04 \pm 0.385$ & $4.79 \pm 0.182$ & $P=0.0839^{* *}$ & -5.83 \\
\hline $\mathrm{LN}$ & 9.1 & $9.35 \pm 0.364$ & $8.26 \pm 0.65$ & $P<0.0002^{* *}$ & 13.91 \\
\hline IB & 5.2 & $4.47 \pm 0.258$ & $4.41 \pm 0.157$ & $P=0.5347$ & 1.32 \\
\hline ZB & 14.2 & $15.03 \pm 0.590$ & $16.04 \pm 0.573$ & $P=0.0062^{*}$ & -6.25 \\
\hline $\mathrm{BBO}$ & 1.9 & $1.87 \pm 0.091$ & $2.28 \pm 0.334$ & $P=0.0006^{* *}$ & -16.46 \\
\hline LB & 7.9 & $8.35 \pm 0.460$ & $7.39 \pm 0.541$ & $P<0.0001^{* * *}$ & 13.50 \\
\hline $\mathrm{BB}$ & 4.8 & $5.02 \pm 0.313$ & $5.41 \pm 0.295$ & $P=0.0191^{*}$ & -6.32 \\
\hline $\mathrm{BBC}$ & 12.5 & $12.95 \pm 0.378$ & $13.34 \pm 0.372$ & $P=0.0290^{*}$ & -2.76 \\
\hline LD & 6.46 & $6.47 \pm 0.195$ & $6.41 \pm 0.482$ & $P=0.4591$ & 1.68 \\
\hline LIF & 2.62 & $2.71 \pm 0.223$ & $2.94 \pm 0.371$ & $P=0.2024$ & -4.71 \\
\hline BIF & 2.21 & $2.51 \pm 0.205$ & $1.88 \pm 0.169$ & $P<0.0001^{* * *}$ & 34.99 \\
\hline Interparietal length & 2.8 & $2.74 \pm 0.37$ & $3.37 \pm 0.528$ & $P=0.475$ & -16.3 \\
\hline Interparietal width & 8.55 & $8.58 \pm 0.55$ & $9.61 \pm 0.717$ & $P=0.0023^{*}$ & -10.16 \\
\hline Anterior palatal breadth & 3.6 & $3.9 \pm 0.21$ & $4.24 \pm 0.402$ & $P=0.0023^{*}$ & -7.5 \\
\hline Posterior palatal breadth & 3.6 & $3.81 \pm 0.11$ & $4.21 \pm 0.35$ & $P=0.0277^{*}$ & -8.64 \\
\hline
\end{tabular}

$*: \mathrm{p}<0.05, * *: \mathrm{p}<0.01, * * *: \mathrm{p}<0.001, \#:(D . y-D . n) \times 100 / D . n$, SD: Standard deviation,

D. y: D. yarkandensis sp., D. $n$ : D. nitedula in northern Xinjiang.

Skull characteristic: There are two pairs of incisors, smaller incisive foramina, developed heekbones, bulky zygomatic arch, bigger auditory bullae, which is separated into several small space by bone membrane on the kull. The dental formula: 1:0:1:3/1:0:1:3. The chewing surfaces of each molar has a few columns of transvrsal enamel teeth ridge. The length of incisive foramina is very close to length of interparietal bone (or incae), which is $11 \%$ of CIL. The ratio of LB to BB is $1.66(8.35 / 5.02)$, and the length of audirory bullae is $2.28(8.35 / 3.66)$ times of upper toothrow length. Junction between interparietal bone and two parietal bone is 130 degrees of a contact angle (figure $2 b$ ). The nasal bone embed into frontal bone with a convex shape (figure $2 \mathrm{~d}$ ). 
bioRxiv preprint doi: https://doi.org/10.1101/2020.02.11.943381; this version posted February 12, 2020. The copyright holder for this preprint (which was not certified by peer review) is the author/funder. All rights reserved. No reuse allowed without permission.

Skull Measurements: The measurement data are shown in Table 1. Basicranial Length: 24.9 (23.9-25.4) mm. Interorbital Breadth: 15 (14,4 -16.1) mm. Length of diastema: 9.35 (8.4-9.9) mm. Breadth of the basioccipital: $1.87(1.8-4.04) \mathrm{mm}$. Length of audirory bullae: 8.35 (4.6-5.2) $\mathrm{mm}$. Upper Toothrow Length: 3.66 (3.53-3.79) mm. Diameter of M3: 1.05 (0.98-1.1) mm. Breadth of incisive foramina: $2.51(2.2-2.86) \mathrm{mm}$. Length of bony palate: 5.04 (4.43-5.61) mm. Breadth of braincase: 12.94 (12.4-13.6) $\mathrm{mm}$. Height of braincase: 11.13 (10.85-12.1) $\mathrm{mm}$.

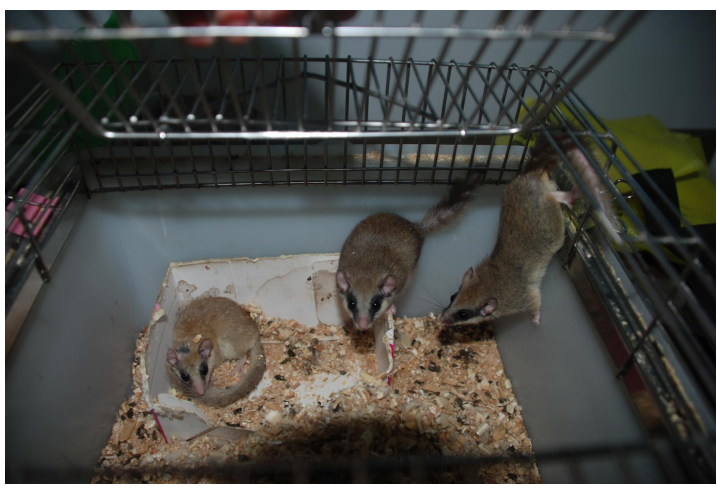

(a)

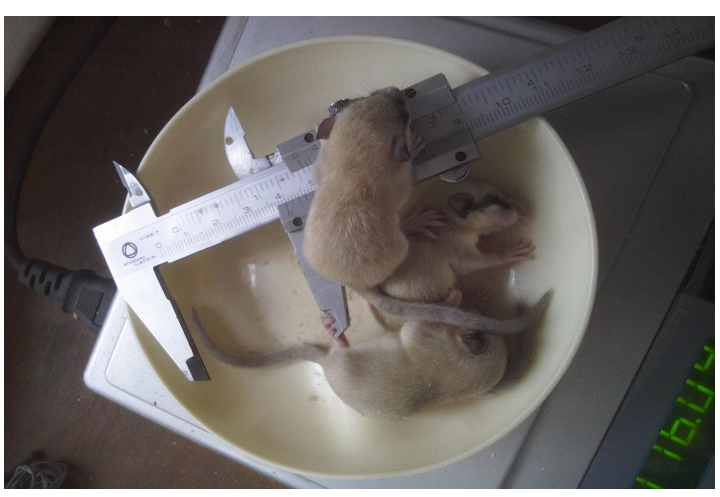

(c)

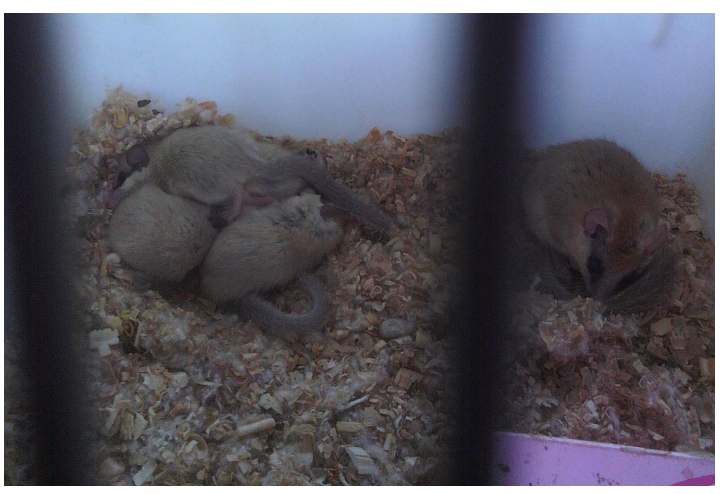

(e)

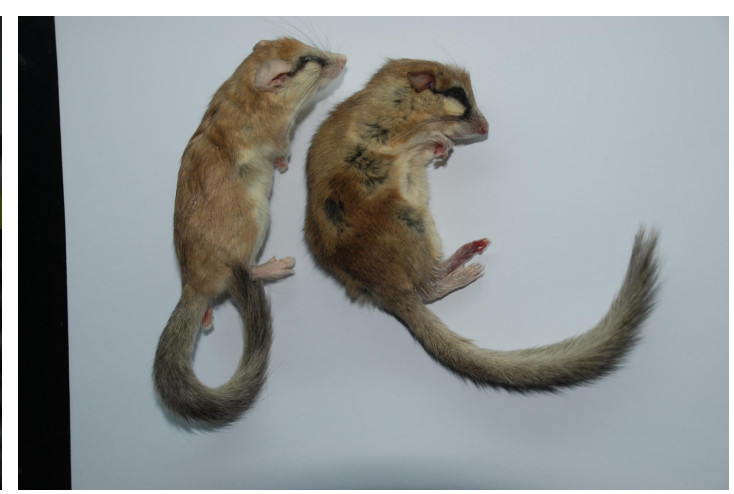

(b)

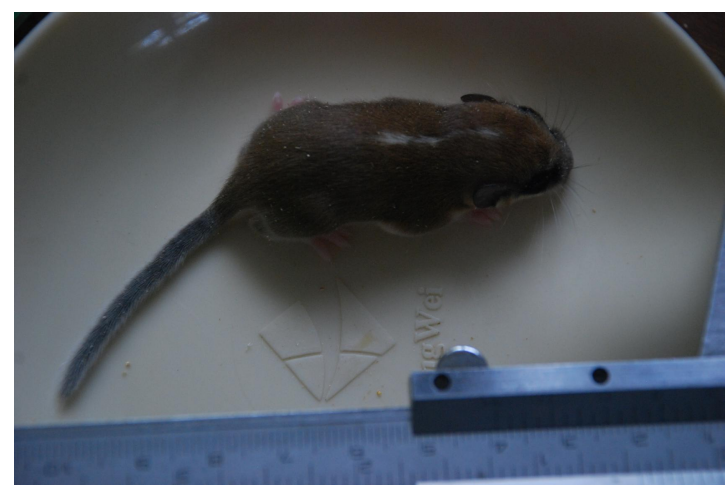

(d)

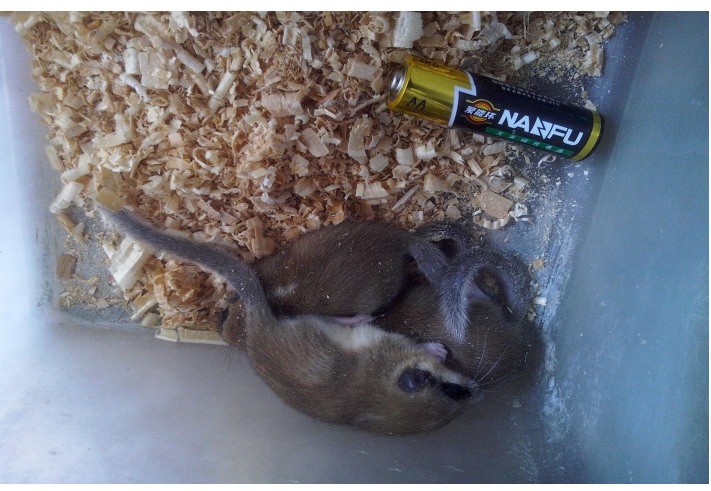

(f)

Figure 1. The coat color of larvae and adults of the new species and D. nitedula in northern Xinjiang.

(a) The coat color of adults of the new species (the left one) and D. nitedula in northern Xinjiang (the right two).

(b) The black stripe from ears across eyes in the new species (the left one) and D. nitedula in northern Xinjiang (the right one).

(c) The 16-day larval of the new species.

(d) The 16-day larval of $D$. nitedula in northern Xinjiang.

(e) The 26-day larval of the new species.

(f) The 26-day larval of D. nitedula in northern Xinjiang. 


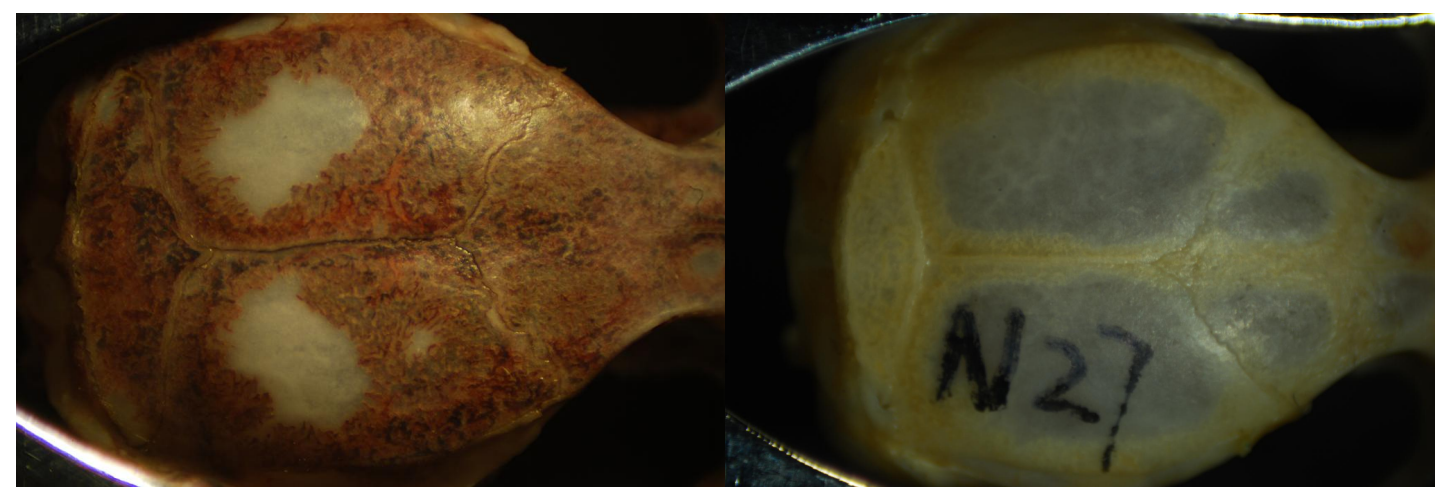

(a)

(b)

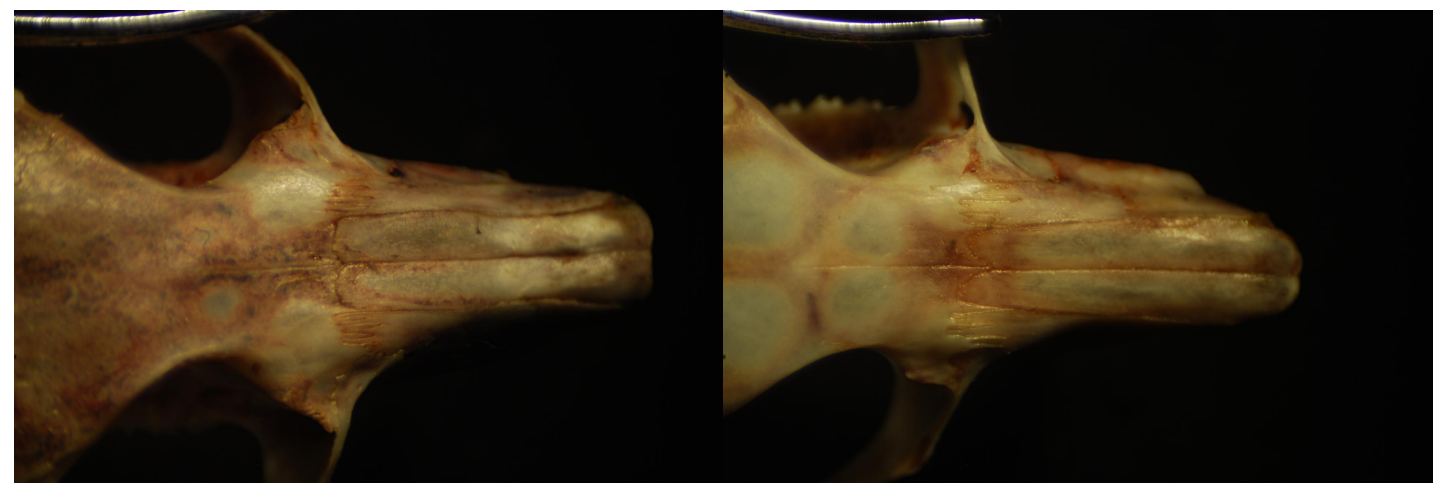

(c)

(d)

Figure 2. Comparison of the nasals and interpariet bone between the new species and D. nitedula in northern Xinjiang.
(a) Interpariet bone of D. nitedula in northern Xinjiang.
(b) Interpariet bone of the new species.
(c) The nasals of $D$. nitedula in northern Xinjiang.
(d) The nasals of the new species.

\section{Identification features of the new species}

By comparing morphology (table 1 and figure 1,2) and statistical analysis (table 2,3), there are differences in geography distribution (figure 3,4) and habitat among the dormice from Tarim basin and the specimens from $D$. nitedulai, D. laniger and $D$. niethammeri. The dormouse from Tarim basin is considered as a new species of the genus Dryomys and named Dryomys yarkandensis sp..

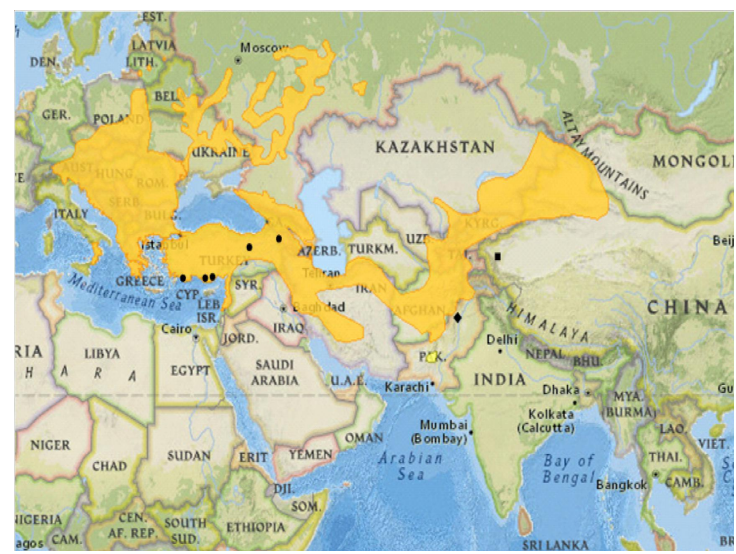

Figure 3. Distribution of different species of the genus Dryomys in Eurasia. The yellow color and the symbol $\bullet$, - represent $D$. nitedula, D. laniger, D. niethammeri and the new species D. yarkandensis sp. respectively. 


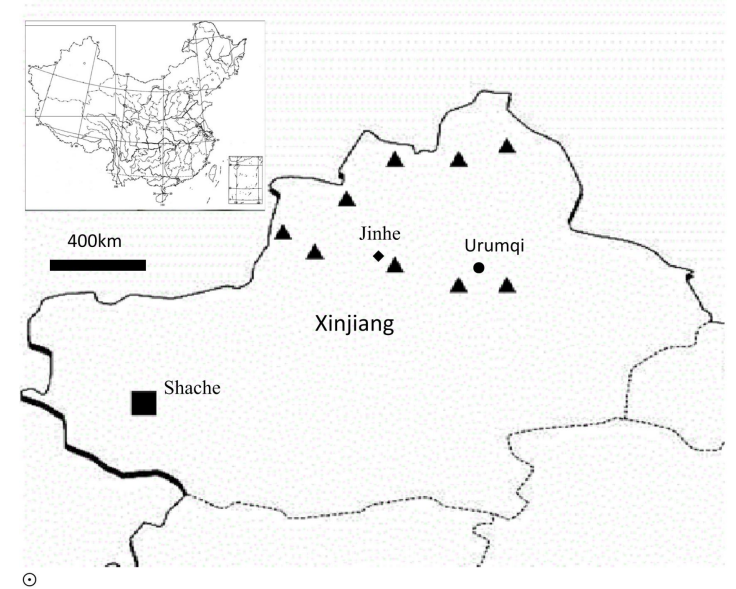

Figure 4. Distribution of the new species D. yarkandensis sp. (₫) and D. nitedula $(\boldsymbol{\Delta})$ of northern Xinjiang in China.

The skull shape of the specimens from Tarim Basin is similar to Muridae, but has a smaller incisive foramina and bigger auditory bullae, which is divided into several small space by bone membrane. There have well-developed cheekbones, thick zygomatic arch and two pairs of incisors on the skull. Dental formula: 1:0:1:3/1:0:1:3. The chewing surfaces of each molar have several columns of transvrsal enamel teeth ridge.

The color of pup is light chestnut from the head to the back (figure 1c,e), and a white on the belly. At autumn the color of back and tail are gradually turn light brown, hair tip of belly become cream yellow, also the color of tail is dark than back and the boundary line between side of the body and belly become clear. The length of incisive foramina is very close to length of Interparietal bone (or incae).

The ratio between length of audirory bullae and breadth of auditory bullae is $1.66(8.35 / 5.02)$, and the length of audirory bullae is 2.28 (8.35/3.66) times of Upper Toothrow Length. Junction between Interparietal bone and two parietal bone is 130 degrees of a contact angle (figure $2 b$ ). The nasal bone embed into frontal bone with a convex shape (figure 2d).

\section{Part 3 Comparison with other three species of the genus Dryomys}

\section{Comparison with D. nitedula in northern Xinjiang}

\subsection{Physical description}

Specimens from Tarim basin: The color of adult on the back is lighter hazel. The color of pup or sub-adult is light chestnut hair from head to back, and a white on belly. There are a light black stripe from ear root through the eye to nose on both sides of the head each (figure 2). The length of the tail is significantly longer than body, more than $10 \%$ of the body length (table 1 ).

D. nitedula from northern Xinjiang: Coat on the body of the adult, pup and sub-adult are russet. The black stripe is darker from ear root through the eye to nose on both sides of the head. The length of tail is equal or less to the length of the body. 


\subsection{Cmparison of skull measurements with D. nitedula from northern Xinjiang}

There are ten indexes of skull measurements in the new species very close to Dryomys in northern Xinjiang, which was not statistically significant (table 2). There are very significant difference in 7 mean values of LN, BBO, LB, UTL, DM3, BIF, LBP and significant difference in the mean value of LN, ZB, BB, BBC, Interparietal width, Anterior palatal bread, and Posterior palatal bread, in which there are four index value (DM3, BBO, Interparietal width and UTL) of new species over $10 \%$ of Dryomys in northern Xinjiang, and three index value (LN, LB and BIF) less than $11 \%$ of $D$. nitedula in northern Xinjiang. The ratio of LB to BB in new species is 1.66 higher than the ratio (1.53) of $D$. nitedula in northern xinjiang. The ratio of LB to length of upper toothrow in the new species is 2.28 , which is large than the ratio in D. nitedula of northern Xinjiang (1.83). The length of incisive foramina is close to the length of interparietal bone in the new species, but only $88 \%$ in $D$. nitedula of northern Xinjiang.

\subsection{Skull and teeth}

Junction between interparietal bone and two parietal bone is 130 degrees of a contact angle in the new species (figure 2b), but less than 70 degree contact angle for D.nitedula of northern Xinjiang (figure 2a). The nasal bone embed into frontal bone with a convex shape for the new species (figure 2d), but with a flat mouthconvex shape for D. nitedulai in northern Xinjiang (figure 2c). There are open angle of two odontoid processes in third molar of maxillary (upper jaw) and four slots of the premolar in the new species (figure 5a), while amall open angle of two odontoid processes in third molar of maxillary (upper jaw) and three slots of the premolar in $D$. nitedula of northern Xinjiang (figure 5c). The transverse diameter of the third molar on mandibular was significantly smaller than that of the second molar in the new species (figure 5b), while the transverse diameter of the third molar on mandibular was slightly smaller than that of the second molar in D. nitedula of northern Xinjiang (figure 5d). The differences of the maxillary of skulls between the two species are shown in table 1-3, and the differences in appearance are shown in figure 6.

Table 3. The measurement values on the new species and the other three species of the genus Dryomys.

\begin{tabular}{cccccc}
\hline \multirow{2}{*}{ Measurement items } & \multicolumn{5}{c}{ Average \pm Standard deviation (n) $\mathrm{mm}$} \\
\cline { 2 - 6 } & D. niethammeri & D. nitedula & D. laniger & D. nitedula in X.J & The new species \\
\hline Body weight (g) & $33(1)$ & $28.9 \pm 7.1(11)$ & $22.2 \pm 3.73(17)$ & $26.4 \pm 4.0(8)$ & $21.91 \pm 1.17(14)$ \\
Head \& body length & $101 \pm 2.82(3)$ & $97.2 \pm 9.7(55)$ & $89.9 \pm 3.96(17)$ & $92.73 \pm 6.51(11)$ & $85.64 \pm 4.45(14)$ \\
Tail length & $93 \pm 0(1)$ & $87.7 \pm 11.88(44)$ & $66.9 \pm 6.15(15)$ & $93.9 \pm 8.61(10)$ & $96.88 \pm 3.28(8)$ \\
Ear length & $19.9 \pm 1.41(2)$ & $14.9 \pm 2.38(52)$ & $14.4 \pm 1.38(16)$ & $16.45 \pm 2.69(10)$ & $12.79 \pm 1.19(14)$ \\
Hind foot length & $21 \pm 0(2)$ & $21 \pm 1.51(55)$ & $16.8 \pm 1.1(17)$ & $20.27 \pm 2.28(11)$ & $21.36 \pm 0.75(14)$ \\
CIL & $25.2 \pm 0.26(3)$ & $23.9 \pm 1.15(56)$ & $23.1 \pm 3.73(17)$ & $25.74 \pm 1.14(11)$ & $24.94 \pm 0.68(14)$ \\
LBP & $5.2 \pm 0.07(2)$ & $5.3 \pm 0.31(37)$ & $5.2 \pm 0.35(15)$ & $4.79 \pm 0.182(9)$ & $5.04 \pm 0.385(14)$ \\
LN & $9.3 \pm 0.26(3)$ & $9.1 \pm 0.44(36)$ & $8.4 \pm 0.47(13)$ & $8.26 \pm 0.65(11)$ & $9.35 \pm 0.36(14)$ \\
\hline
\end{tabular}


bioRxiv preprint doi: https://doi.org/10.1101/2020.02.11.943381; this version posted February 12, 2020. The copyright holder for this preprint (which was not certified by peer review) is the author/funder. All rights reserved. No reuse allowed without permission.

\begin{tabular}{cccccc}
\hline IB & $3.9 \pm 0.15(3)$ & $4.1 \pm 0.19(39)$ & $4.2 \pm 0.16(18)$ & $4.41 \pm 0.16(11)$ & $4.47 \pm 0.26(14)$ \\
ZB & $15.9 \pm 0(1)$ & $15.7 \pm 0.85(30)$ & $14.4 \pm 0.47(13)$ & $16.04 \pm 0.57(5)$ & $15.03 \pm 0.59(14)$ \\
BBO & $1.4 \pm 0.1(3)$ & $2 \pm 0.26(57)$ & $1.4 \pm 0.16(16)$ & $2.28 \pm 0.33(9)$ & $1.87 \pm 0.09(14)$ \\
LB & $9 \pm 0.15(3)$ & $7.3 \pm 0.45(60)$ & $8.1 \pm 0.21(18)$ & $7.39 \pm 0.54(11)$ & $8.35 \pm 0.46(14)$ \\
BB & $5.9 \pm 0.15(3)$ & $5 \pm 0.29(55)$ & $5.3 \pm 0.18(17)$ & $5.41 \pm 0.30(9)$ & $5.02 \pm 0.31(14)$ \\
LB/BB & 1.53 & 1.46 & 1.53 & 1.37 & 1.66 \\
BBC & $12.9 \pm 0.75(3)$ & $12.8 \pm 0.39(37)$ & $12.6 \pm 0.26(12)$ & $13.34 \pm 0.37(11)$ & $12.95 \pm 0.38(14)$ \\
LD & $6.3 \pm 0.2(3)$ & $6.3 \pm 0.34(39)$ & $5.8 \pm 0.25(18)$ & $6.41 \pm 0.48(11)$ & $6.47 \pm 0.20(14)$ \\
LIF & $3.9 \pm 0.06(3)$ & $3.6 \pm 0.29(39)$ & $3.4 \pm 0.2(17)$ & $2.94 \pm 0.37(9)$ & $2.71 \pm 0.22(14)$ \\
BIF & $2.2 \pm 0.06(3)$ & $2 \pm 0.19(39)$ & $1.9 \pm 0.11(18)$ & $1.88 \pm 0.17(7)$ & $2.51 \pm 0.21(14)$ \\
\hline
\end{tabular}

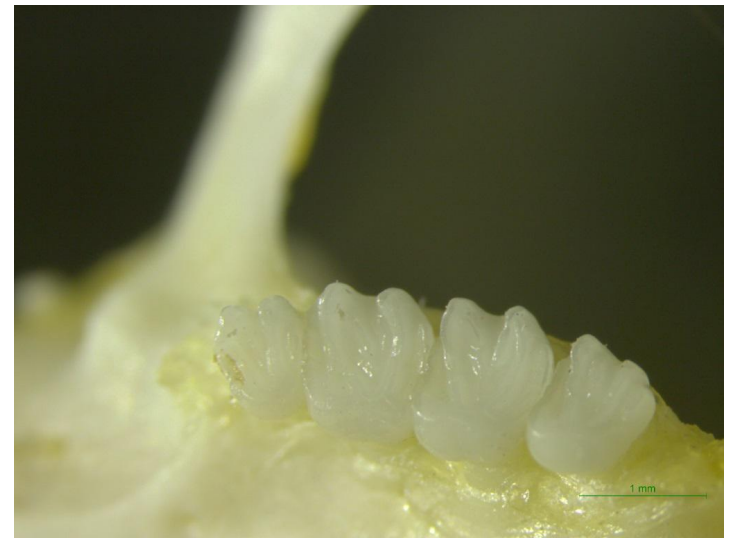

(a)

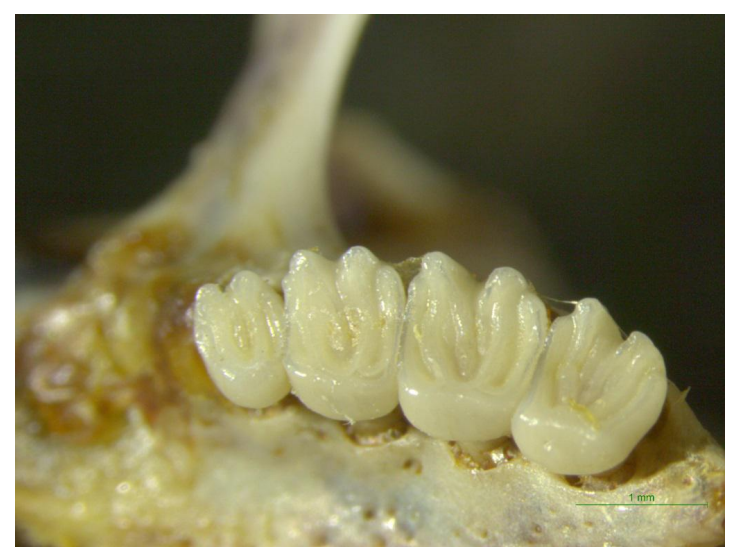

(c)

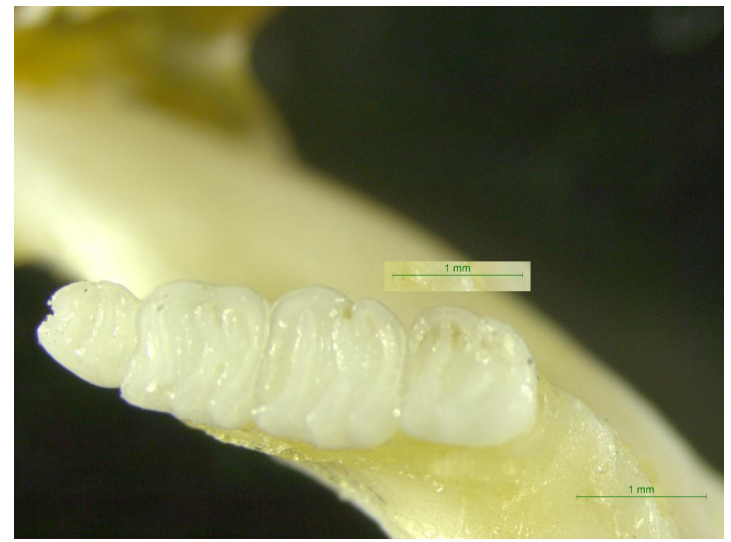

(b)

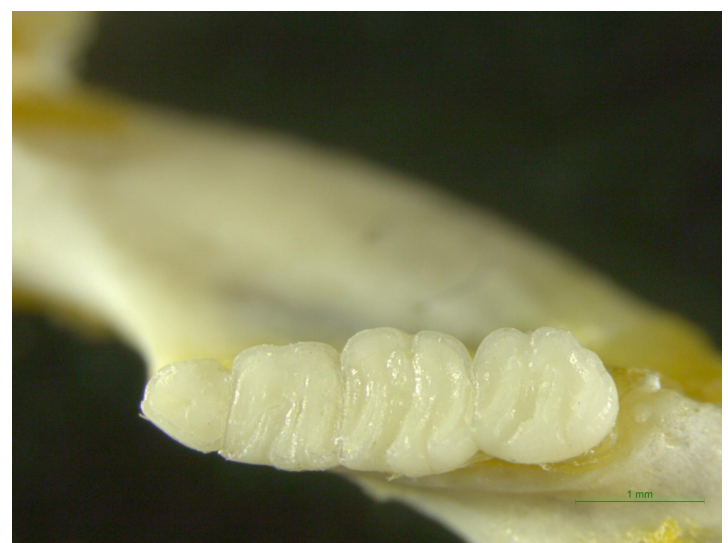

(d)

Figure 5. Comparisons of the crowns between the new species and D. nitedula in northern Xinjiang.

(a) The dentition on left side of maxillary in the new species.

(b) The dentition on left side of mandible in the new species.

(c) The dentition on left side of maxillary in D. nitedula in northern Xinjiang.

(d) The dentition on left side of mandible in D. nitedula in northern Xinjiang.

\subsection{Habitat comparison}

The new species is distributed in the desert oasis orchard, $1200 \mathrm{~m}$ above sea level in Tarim 
bioRxiv preprint doi: https://doi.org/10.1101/2020.02.11.943381; this version posted February 12, 2020. The copyright holder for this preprint (which was not certified by peer review) is the author/funder. All rights reserved. No reuse allowed without permission.

Basin. The climate there is harsh, drought and hot in summer but dry and cold in winter (figure 7a). D. nitedula in northern Xinjiang is mainly distributed in mountain valley between $700 \mathrm{~m}$ to 1200 $\mathrm{m}$ above the sea level. The climate there is temperate, humidity and low temperature, and there are berries or orchard (figure $8 \mathrm{~b}$ ). It is obvious difference for the climates and habitats between the two distributions.

The color over the back of a new species is similar to yellow sand of the habitat backgrounds. The color of D. nitedula in northern Xinjiang is similar to brown of coniferous forest or dwarf shrub of the mountains in northern Xinjiang. This significant differences in color protection takes the dormouse to survive in them habitats.

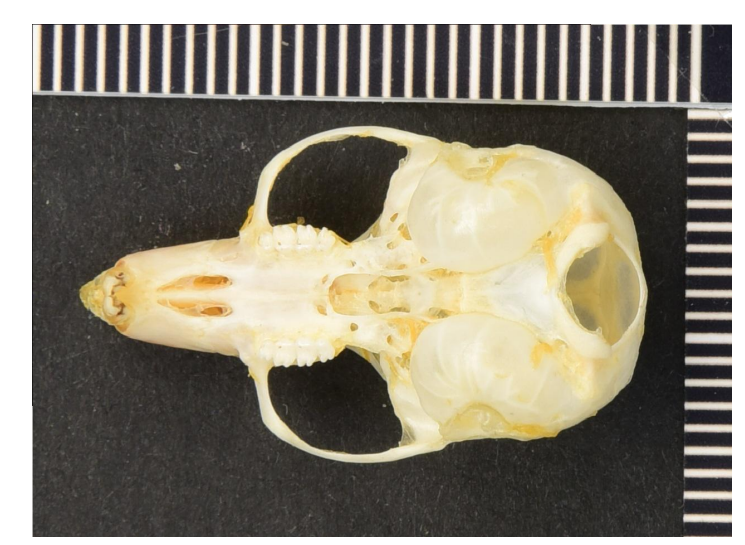

(a)

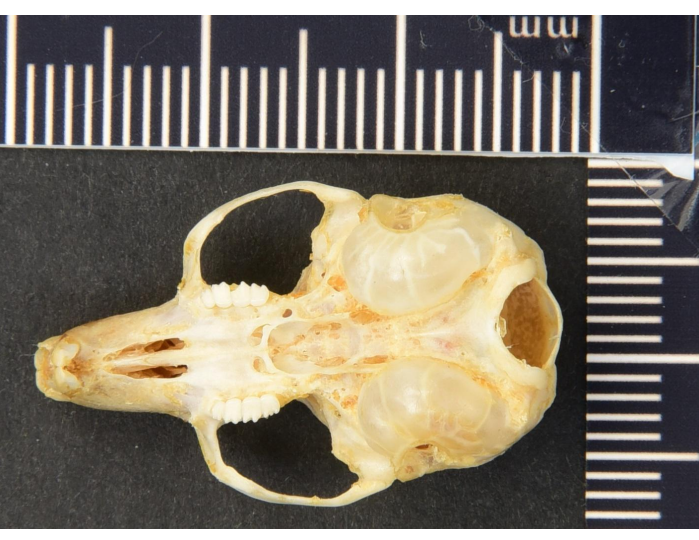

(b)

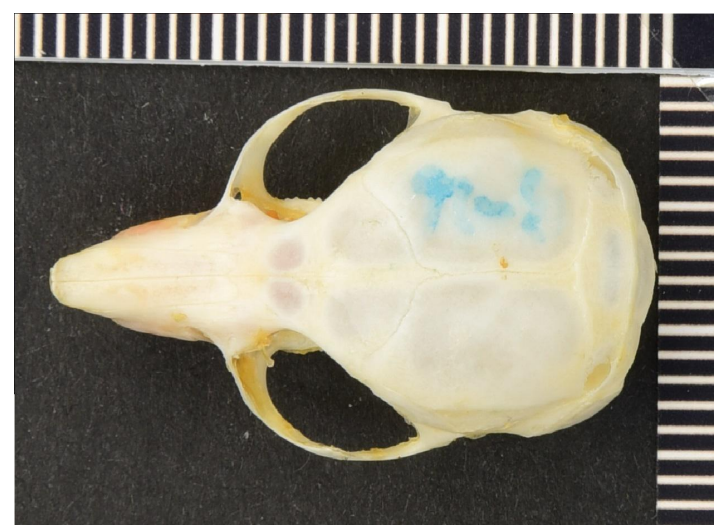

(c)

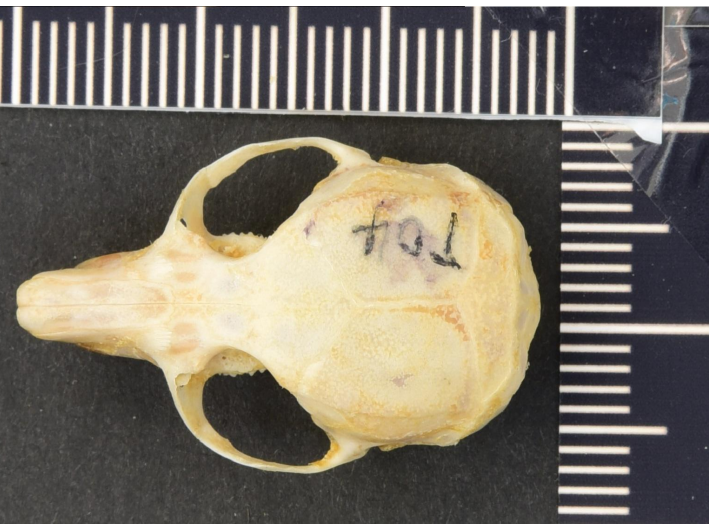

(d)

Figure 6. Comparison of the skulls between the new species and D. nitedula in northern Xinjiang. T04 is $D$. nitedula in northern Xinjiang and N07 is the new species D. yarkandensis sp..
(a) Ventral view of maxillary for D. yarkandensis $s p$.
(b) Ventral view of maxillary for D. nitedula.
(c) Dorsal view of maxillary for D. yarkandensis sp.
(d) Dorsal view of maxillary for D. nitedula.

\section{Comparison with other three species in Dryomye}

\subsection{Comparison of morphology}

The adult of new species displays a lighter color of bodily hair on the back than that of other three species of Dryomye, and the black spot, which spread on both sides of head from the rear of 
nose, through eyes, then to the front of ears, is lighter-color than that of other three species of Dryomye. The LT of a new species obviously exceeds its LHB by $10 \%$, however, the LTs of the other three species in Dryomye are less than or equal to body length (table 2,3).

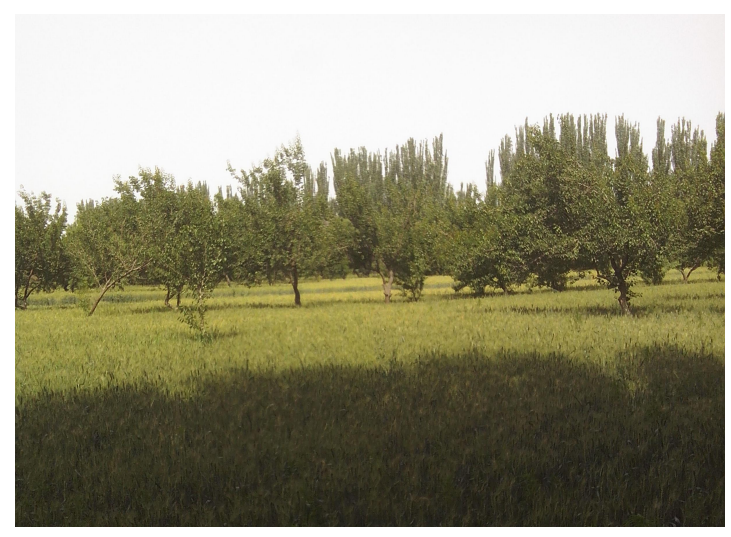

(a)

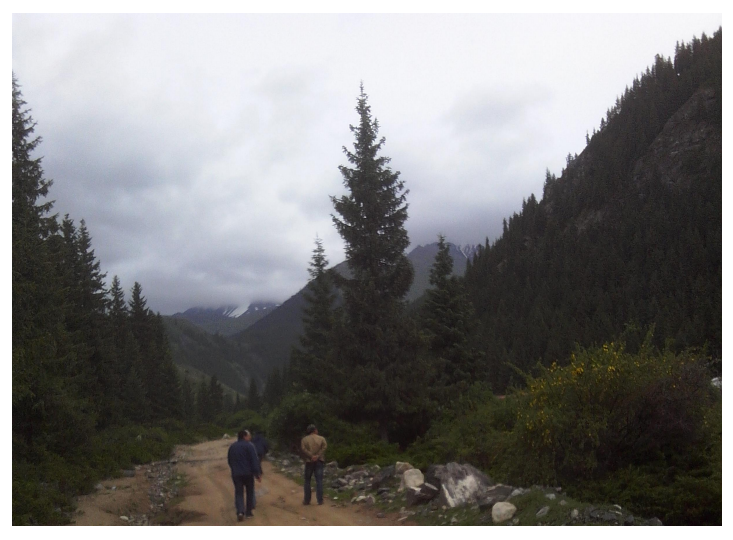

(b)

Figure 7. Habitat of (a) the new species and (b) D. nitedula in northern Xinjiang.

\subsection{Comparison of skull measurements}

As shown in figure 8 and table 3, the main different features between the new species and $D$. laniger are focused on LT, BIF, and BBO. Accordingly, the difference related to D. niethammeri and D. nitedulai are focused on LE, LIF, BBO and LHB, LT, LE, LIF, LB, BB, BBO, respectively. The ratio of $\mathrm{LB}$ to $\mathrm{BB}$ in the new species (1.66) is apparently higher than 1.40 in D. laniger, 1.53 in D. niethammeri and 1.46 in D. nitedulai. The ratio of LB to LD is 1.29 in the new species, while 1.4 in D. laniger, 1.43 in D. niethammeri and 1.16 in D. nitedulai.

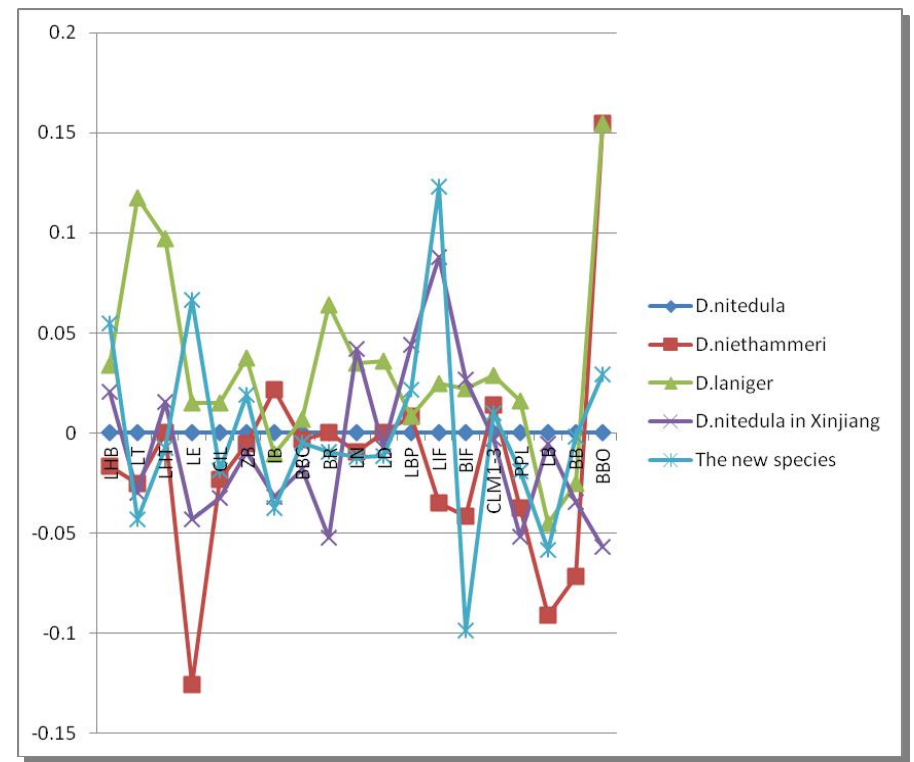

Figure 8. Comparison of the measured values between the new species and other species of Dryomye.

\section{Classified discussion}

According to the observed value of morphology and the skull measurements, the new species of Tarim Basin differs significantly in morphological from D. nitedulai, D. laniger and $D$. 
niethammeri. Also considering the results of differences among habitats, we identified that the species of Tarim Basin is a new species, and its molecular genetics identification is going to further research. As a new species, it still remains empty for its distribution range, population situation and biological characteristics. It is urgent to develop further research on the new species from viewpoint of protection biology.

Distribution: The new species specimens had been obtained from this point in Tarim Basin only at present, other areas did not investigate in Xinjiang (figure 7b).

Biology data: Missing.

Check samples: 11 specimen of D. nitedula from northern Xinjiang, 6 deposited in Institute of Zoology, Chinese Academy of Sciences, $21247 \delta^{\lambda}$ in Altai county, $21752+$ in Fukan county, $26659 q$ in Manashi county, $26708 q$ in Nileke county, $27482 q$ and $27481 q$ in Sawuer mountain; 5 specimens deposited in the Herbarium of Xinjiang CDC, T3 $q$, T4 + , T5 $ぇ$, T31 q and T32 $\delta$ from Jinghe county of northern Xinjiang.

Reference sample data: from previous work (Holden, 1996).

D. niethammeri: $\mathrm{n}=3$, Pakistan, 3 q.

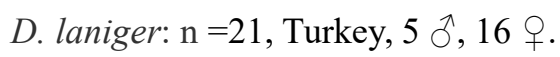

D. nitedulai $\mathrm{n}=85$, Afghanistan $\mathrm{n}=10(5 \circ, 5 \AA)$, Austria 2 , , Albania 1 , , Croatia $\mathrm{n}=2(1 \lesssim, 1$ ),

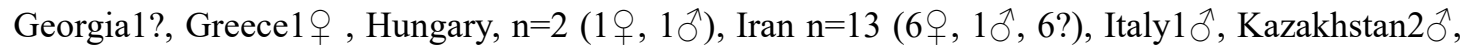

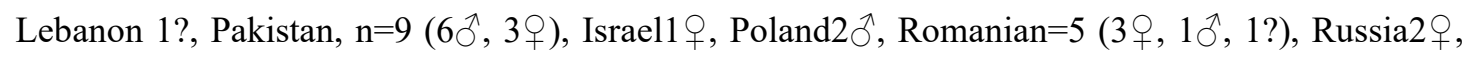
Sweden1 $\hat{\partial}$, Turkey $n=23(11$, $, 10 \hat{\jmath}, 2$ ?), Former-Yugoslavia, $n=7$ (3ㅇ, $3 \hat{\jmath}, 1$ ?).

\section{Acknowledgment}

First of all, we would like to thank Professor Yong MA in Institute of Zoology, the Chinese Academy of Sciences, for kind guidance on this article. For permission to conduct research in Xinjiang, we would like to thank Zhenghai CHENG for his contributions to information and collecting samples from Tarim Basin. The data were measured and the samples were raised in our lab with the help of students, especially Xinhui LI and Xiaoyan LIAO in Xingjiang Agricultural University.

\section{References}

Airapetyants, A.A., Fokin, I.M., 2005. The Forest dormouse Dryomys nitedula (Pallas, 1779). www.biodiversity.ru/programs/rodent/species/dryomys nitedula.html.

Allen, G., 1940. The mammals of China and Mongolia pt.2. Amer. Mus. Nat., New York.

Bosessneck, J., Driesch, A., 1976. The Significance of Measuring Animal Bones from Archaeological Sites. In:

G.Riek ed. Das Paläolithikum der Brillenhöhle bei Blaubeuren, Reil II. Oxford:Stut tgart Clarendon Press.

Driesch, A., 1976. A Guide to the Measurement of Animal Bones from Archaeological Sites. Peabody Museum

Bulletin 1. Peabody Museum of Archaeology and Enthnology. Cambridge, MA: Harvard University Press.

Ellerman, J.R., Morrison-Scoot, T.C.S., 1951. Checklist of Palaearctic and Indian mammala. 
Felten, H., Storch, G., 1968. Eine neue Schlafer-Art, Dryomys laniger n. sp. Aus Kleinasien (Rodentia, Gliridae). Senckenbergiana biol., 49(6): 429-435.

Holden, M.E., 1996. Description of a new species of Dryomys (Rodentia, Myoxidae) from Balochistan, Pakistan, including morphological comparisons with Dryomys laniger Felten and Storch,1968, and D.nitedula (Pallas, 1778). Bonner Zoologische Beiträge, 46(1-4): 111-131.

Holden, M.E., 2005. Mammal Species of the World a Taxonomic and Geographic. Wilson, D.E. and Reeder, D.M. eds. Johns Hopkins University Press, Baltimore.

Kashtal, Y.A.P., 1997: Representatives of Dormouse family (Gliridae) at the territory of Belarus. Republic. In: Anon., ed. Rare mammalian species of Russia and adjacent territories (Proc. of International conference, Moscow, 9.11 April 1997). Moscow: IPEE, p. 47 (Russian).

Kryštufek, B., 1985. Forest dormouse Dryomys nitedula (Pallus 1778) Rodentia, Mammolia in Yugoslavia. Scopolia, (9): 1-36.

Kryštufek, B., Vohralik, V., 1994. Distribution of the Forest Dormouse Dryomys nitedula (Pallas, 1778) (Rodentia, Myoxidae) in Europe. Mammal Review, 24(4): 161-177.

Kryštufek, B., 1999. Dryomys nitedula. In: A. J. Mitchell-Jones, G. Amori, W. Bogdanowicz, B. Kryštufek, P. J. H. Reijnders, F. Spitzenberger, M. Stubbe, J. B. M. Thissen, V. Vohralík and J. Zima (eds), The Atlas of European Mammals, 300-301.

Ma, Y., Wang, F., Jin, K., Li, S., 1987. Rodents'Classification and Distribution in the North of Xinjiang. Beijing. Science Press. 210-213.

Ognev, S.I., 1940. Mammals of the USSR and adjacent countries: Rodents. Akademiya Nayk SSSR.

Огнев, С.И., 1947. Звери СССР и прилежащих Страи, Тот.5 Изд. АН СССР.М. - Л. 431.

Rossolimo, O.L., Potapova, E.G, Pavlinov, I.Y, Kruskop, S.V., Voltzit, O.V., 2001. Dormice (Myoxidae) of the World. Sbornik Trudov Zoologicheskogo Muzeya MGU, 42: 1-232.

Shiirevdamba, Shagdarsuren, O., Erdenejav, G., Amgalan, T., Tsetsegmaa, T., 1997. Mongolian Red Book. Ministry of Nature and Environment. Admon Printing, Ulaanbaatar.

Sisson, S., Grossman, J.D., 1950. The Anatomy of the Domestic Animals. 4th edition. Philadelphia \& London: W. B.Saunders and Company.

Sludskii, A.A., 1977. The Forest dormouse. In: Mammals of Kazakhstan. Vol. 1, part II (Rodents). Alma-Ata: Nauka, 116-137.

Sokolov, V.E., 1977. Systematics of Mammals vol.2 Lagomorphs and Rodents.Vysshaya Shkola, Moscow.

Thomas, O., 1906. New Asiatic mammals of the genera Kerivoula Eliomys and Lepus, Ann. Mag. Nat. Hst., (7)17: 423.

Wang, S., Yang, G., 1983. Rodent Fauna in Xinjiang. Urumqi.Xinjiang People Press, 88-90.

Xia, L., Yang, Q., Ma, Y., Feng, Z., Zhou L., 2006. A Guide to the Measurement of Mammal Skull, Rodentia and Lagomorpha, Chinese Journal of Zoology, 41(5): 68-71.

Yang, Q., Xia, L., Ma, Y., Feng, Z., Quan, G., 2005. A Guide to the Measurement of Mammal Skull: Basic Measurement. Chinese Journal of Zoology, 40(3): 50-56.

Zhang, R., 1997. Distribution of Mammalian Species in China. China forestry Press. 